Л. Л. Иомдин

ИППИ РАН им. А. А. Харкевича, г. Москва

iomdin@iitp.ru
УДК 811.161.1'367.624

https://doi.org/10.18485/slavistika.2018.22.1.5

оригинални научни рад примљено 26.03.2018.

прихваћено за штампу 28.04.2018.

\title{
О НЕКОТОРЫХ РАЗГОВОРНЫХ КОНСТРУКЦИЯХ С ПРЕДИКАТИВНЫМИ НАРЕЧИЯМИ В РУССКОМ ЯЗЫКЕ*
}

Статья посвящена сравнительно новому классу русских разговорных микросинтаксических конструкций с предикативными наречиями и номинативными подлежащими типа $T b l$

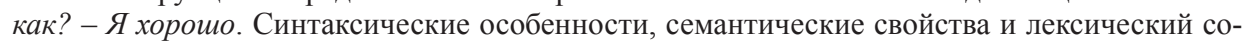
став этих конструкций рассматривается в сопоставлении с классом безличных конструкций с предикативными наречиями и дативным субъектом типа Мне хорошо, а также с рядом других конструкций, семантически и синтаксических близких к данному классу.

Ключевые слова: русский язык, микросинтаксис, предикативные конструкции, предикативные наречия, номинативное подлежащее, дативный субъект.

The paper focuses on a relatively new class of Russian microsyntactic colloquial constructions with predicative adverbs and nominative subjects like Ty kak - Ja xorošo $\approx$ 'How are you? - I am well'. The syntactic behavior, semantic features and lexical composition of these linguistic units are compared with those of a different class of impersonal predicative adverbial constructions in which the subject is expressed by the dative, as in Mne xorošo ('lit. to me is good) 'I am feeling good'. Other constructions with close semantic and syntactic properties are also considered.

Keywords: Russian, microsyntax, predicative constructions. predicative adverbs, nominative subject, dative subject.

\section{1. Новый класс конструкций}

В последнее время в русистике весьма активно обсуждаются различные аспекты, казалось бы, давно и хорошо изученных конструкций, формируемых предикативными словами (прилагательными, наречиями или представителями т.н. категории состояния), выступающими в составе сказуемого с эксплицитной или нулевой связкой:

(1) Ему тяжело говорить об этом,

(2) Мне грустно ... потому, что весело тебе (М. Ю. Лермонтов),

(3) Вольно́ было вам шептать (В. В. Набоков),

(4) Как здорово, что все мы здесь сегодня собрались (О. Митяев),

(5) Ребенку может быть обидно, если его не возьмут в ияирк и т.д.

С развитием корпусов текстов и передовых корпусных технологий обнаруживаются новые и уточняются известные синтаксические, лексические, семантические и диахронические особенности таких конструкций, вводятся в научный оборот дополнительные классы релевантных единиц. Из работ последних лет на эту тему следует отметить, в частности, статьи Циммерлинг 2010, 2012, 2017, Say 2013, Летучий 2014.

* Автор выражает признательность за поддержку данной работы Российскому научному фонду (грант № 16-18-10422). 
Однако, несмотря на возросший интерес к предикативам, один класс содержащих их русских конструкций удивительным образом остается вне поля зрения исследователей и не находит адекватного отражения ни в словарях, ни в теоретическом синтаксисе. Мы имеем в виду разговорные конструкции типа

(6) $T$ ть как?,

(7) Я хорошо.

На наш взгляд, эти конструкции достаточно близки к приведенным выше, хотя и отличаются от них в одном важном отношении: в конструкциях типа (1)-(5) субъект состояния, если он есть, выражен дательным падежом, а в данных конструкциях субъект состояния выражен более прототипическим (но необычным в отсутствие согласуемых сказуемых) именительным падежом. Мы попытаемся заполнить эту лакуну, исходя из понимания такого материала как явлений микросинтаксиса (см., например, Иомдин 2014, 2015, 2017) или, несколько шире, как явлений грамматики конструкций: последние отечественные работы в рамках такого подхода включают, в частности, Рахилина 2010 и Добровольский 2016.

В письменном тексте такие конструкции встречаются редко и по этой причине достаточно трудны для обнаружения привычными исследовательскими методами. Эти конструкции, однако, весьма распространены в современной бытовой устной речи, причем такой, которая в массовом порядке в письменной передаче не воспроизводится (некоторое исключение тут составляют театральные пьесы, а также мгновенные сообщения типа SMS). В первую очередь они свойственны кратким диалогам, в которых первая реплика представляет собой обращенный к собеседнику вопрос, а вторая - спонтанный ответ на этот вопрос:

(8а) Скажи честно, как ты сегодня? - (8б) Не волнуйся, я вполне хорошо;

(9а) А что бабушка? - (9б) Бабушка с утра была неважно, видимо, плохо спала ночью.

В отсутствие представительных данных при анализе этих конструкций исследователь вынужден в значительной мере опираться на интроспекцию и отчасти на эксперименты с участием информантов.

\section{2. Синтаксис}

Синтаксические свойства этих конструкций отличаются ярко выраженной спецификой. Вопрос в диалоге рассматриваемого нами типа чаще всего формируется наречием как в роли сказуемого (с нулевой связкой или, реже, реальным глаголом быть в личной форме и прошедшем/будущем времени) и подлежащим в именительном падеже. В ответной реплике роль сказуемого выполняет наречие ограниченного лексического класса, чаще всего с финалью - $O$, также с имплицитной или эксплицитной связкой.

Частеречный статус такого наречия не подлежит сомнению: его нельзя трактовать ни как краткую форму прилагательного (поскольку, при наличии связки, последняя должна была бы согласовываться с прилагательным по роду и числу, что в данных конструкциях невозможно, ср.

(10) Бабушка была $<*$ было> неважно,

(11) Дети были <*было> неплохо), 
ни как категорию состояния (если вообще признавать такую часть речи отдельной сущностью ${ }^{1}$ ).

Последнее легко установить, сравнив семантику конструкций типа

(12) Мне хорошо,

с одной стороны, и

(7) Я хорошо,

с другой: в (12), в отличие от (7), речь идет о внутреннем состоянии субъекта, а (7) скорее характеризует общее положение вещей, хотя, конечно, оно и связано с субъектом. Тем самым рассматриваемые конструкции заметно расширяют круг употреблений предикативных наречий в русском языке.

\section{3. Семантика}

Семантика рассматриваемых здесь конструкций достаточно конкретна: она касается физического состояния или жизненных обстоятельств протагониста конструкции. В упомянутой ситуации краткого диалога типа (8-9) как вопрос ${ }^{2}$, так и ответ касаются физического состояния или жизненных обстоятельств самого отвечающего собеседника или кого-то, принадлежащего к личной сфере этого собеседника (а опосредованно и к личной сфере вопрошающего, которая непременно включает в себя отвечающего собеседника). Трудно представить себе серьезный обмен репликами между московскими пенсионерами типа

(13) - Вы ведь недавно были в Японии? Как там император Акихито? Он чудесно.

Комичность диалога (13) объясняется именно нарушением требования принадлежности протагониста к личной сфере собеседников.

Добавим, что в таких конструкциях субъект ситуации обязательно имеет конкретно-референтный статус: предложения типа

(14) *Как пациенты после таких операщий?

${ }^{1}$ По мнению автора, категорию состояния как особую часть речи постулировать не следует. В синтаксической концепции, восходящей к синтаксическому компоненту теории «Смысл $\Leftrightarrow$ Текст» И. А. Мельчука, которой придерживается автор и его коллеги (см., например, Апресян и др. 2010), предикативные слова типа тяжело, грустно, как в примерах (1)-(2), считаются прилагательными (в краткой форме ср. рода), а слова типа вольно́, здо́рово, боязно, жаль, не имеющие омонимичной пары среди прилагательных - наречиями, обладающими особым признаком предикативности. Заметим, впрочем, что противопоставление прилагательных и наречий вообще довольно условно и, возможно, требует пересмотра в русской грамматике. Подробно обсуждать эту проблему мы здесь не будем; ограничимся лишь указанием, что во многих наречных и адъективных парадигмах, разделяющих одну основу, совпадают не только словоформы краткого прилагательного и наречия (хорошо), но и формы сравнительной степени (лучше), а рассматривать многозначность форм в конструкциях типа он хорош - он хороший - он хорошо - ему хорошо - он лучше - ему лучше можно и не прибегая к их частеречной идентификации. Добавим, что по крайней мере одна из этих единиц (средне) не имеет омонимов среди форм прилагательного.

2 Заметим, что сам по себе вопрос типа Как $X$ ? необязательно предполагает ответ типа (8б) и тем самым может не затрагивать личной сферы участников диалога; ср. Как ваш новый директор?, Как картина, которую тебе подарили?: он приобретает такое свойство лишь в диалогах рассматриваемого типа. 
(15) *Кто-нибудь отлично,

(16) *Маленький ребенок при такой температуре может быть даже неплохо кажутся в высшей степени сомнительными.

Как представляется, к личной сфере собеседников относятся и диалоги с участием глагола поживать, который описывает примерно тот же класс ситуаций, что и рассматриваемые выше конструкции, и часто употребляется вместе с последними:

(17) Ну, как поживаешь? - спросил он. - Нормально, - ответил я. - Не жалуюсь. (Мариам Петросян);

(18) Мое почтенье... Как поживаете? Я - ничего себе... (Борис Горбатов, Непокоренные: здесь все реплики принадлежат одному человеку)

(19) А вы как пожсиваете? - Я? Ничего: здорово и весело, - очень весело! - с чувством прибавил молодой человек. (И.А. Гончаров, Обломов: здесь имеет место диалог).

Интересно, что глагол поживать, несмотря на принадлежность к личной сфере, несколько парадоксальным образом используется (точнее, использовался, поскольку в настоящее время он устаревает) в ситуациях формального, «этикетного» общения. По-видимому, вследствие последнего обстоятельства он ошибочно попал в рекомендуемые формулы учебников русского языка как иностранного. Эта противоречивость личной сферы и формального речевого регистра для поживать отлично иллюстрируется следующей выдержкой из детской повести:

(20) - Я вас знаете как искала? Через справочное бюро, очень просто. Всего за десять копеек дают адрес. Почему-то люди любят начинать разговор не с главного. Не с того, что их по-настоящему занимает. Так им почему-то легче. Ну, нашла она меня за гривенник. А дальше что? - Как вы поживаете? Приходится сдержать смех. Вдруг такая приличная, светская. «Как вы поживаете?» Это она-то. Как будто не её мы тогда за пятки с верхней полки стаскивали.- Прекрасно поживаю. Пишу книгу, большую повесть о твоих ровесниках. (Л.Г.Матвеева, Мы в пятом классе).

Зато конкурирующие конструкции с предикативом и дательным субъекта типа (1-5) не требуют апелляции к концепту личной сферы: высказывания с такими конструкциями вполне могут касаться ситуаций, затрагивающих посторонних для говорящего субъектов, которые даже могут иметь родовой денотативный статус (как в (5)). Это еще одно заметное отличие конструкций с дативным субъектом от конструкций с номинативом.

Еще одна тонкая семантическая особенность рассматриваемых конструкций с номинативным подлежащим, отличающая ее от конструкций с дативным субъектом, состоит в следующем. Конструкция типа Я хорошо отражает ситуацию, продолжающуюся в течение определенного времени, которая оценивается говорящим как достаточно устойчивая (возможно, на основании обобщения имплицитной информации - см. об этом ниже). Она не может употребляться для представления мимолетного, сиюминутного внутреннего состояния субъекта, как это часто бывает в дативных конструкциях. Ср.:

Славистика XXII/1 (2018) 
(21a) Маме плохо, срочно вызывай скорую помощь, при сомнительности

(21б) "'Мама плохо, срочно вызывай скорую помощь.

\section{4. Лексикография}

Особый интерес представляет, на наш взгляд, лексический состав класса слов, способных появляться в таких конструкциях. Кроме наречий как и что, формирующих прямой (как в примерах (8) и (9)) или косвенный вопрос типа

(22) Я спросила у него, как Петя, он молча показал мне его в толпе, стоявшей в ногах у гроба (В. Каверин),

в этих конструкциях могут выступать наречия общей оценки, как положительной, ср.

(23) Он хорошо <отлично, прекрасно, чудесно, классно, обалденно, офигенно, неплохо, ничего >

так и отрицательной:

(24) Он неважно <средне, плоховато, плохо, паршиво>

Разумеется, можно в этой конструкции представить себе и другие экспрессивные наречия положительной и отрицательной оценки, вплоть до табуированных наречий или их эвфемистических эквивалентов: обалденно, офигенно, охренительно, хреново, фигово ${ }^{3}$.

Что касается таких наречий, выражающих нейтральную оценку, то их, по всей видимости, очень немного. К ним относятся разве что наречия обыкновенно и обычно:

(25) Ты как сегодня? - Я обыкновенно, не хуже и не лучше, чем вчера.

В то же время наречия ничего, нормально и средне, по внутренней форме, казалось бы, тяготеющие к нейтральной оценке, на самом деле демонстрируют разнонаправленный семантический сдвиг: ничего и нормально несут положительную оценку, а средне - отрицательную. Это особенно заметно в контексте степенного наречия типа очень, весьма или совсем, ср.

(26) Она с утра очень даже ничего,

(27) Знаешь, я что-то весьма средне.

Конструкция с наречием нормально в рассматриваемых контекстах распространена, пожалуй, чаще всего; она регулярно представлена и в разговорных ситуациях, представленных письменно, ср.

(28) Я нормально / недавно познакомилась с мальчиком / его зовут Ваня (Устный подкорпус НКРЯ);

\footnotetext{
${ }^{3}$ Обращает на себя внимание то, что разные эвфемистические наречия, образованные от одной основы, выражают полярные оценки: офигенно и охренительно означают 'хорошо', а фигово и хреново - 'плохо'. Это, разумеется, относится не только к рассматриваемым конструкциям, но и к любым типам употреблений таких наречий (а также и соответствующих прилагательных); ср. Говорят, счастье тебя обязательно найдет. Не пойму: или я так офигенно прячусь, или оно меня как-то фигово ищет... (петербургское юмористическое издание «Прикол», 2004). Автор признается, что не знает, почему это так, и вынужден присоединиться к ответу на вопрос блогера "Почему «офигенно» - это хорошо, а «фигово» - это плохо?”, данному экспертом блога bolshojvopros.ru: “Так уж устроен русский язык”.
} 
(29) [Самохвалов] Да я нормально. Последние два года работал в Женеве. (Э. Рязанов, Э. Брагинский. Служебный роман, к/ф).

В самое последнее время наречие нормально (и прилагательное нормальный) приобрело в молодежном жаргоне сокращенный вариант норм, используемый в том числе в конструкциях с дативным субъектом (мне норм) и при номинативном подлежащем (я норм - правда, в последнем случае бывает непросто различить интерпретации 'я нормально' и 'я нормальный').

В конструкциях с номинативным субъектом появляются и наречия, задающие тот или иной тип сравнения; ср.

(30) - Как твои дети? - Они по-разному, Петя хорошо учится, а Вася из двоек не вылезает,

(31) Мы по-прежнему <по-старому>

(но, странным образом, не * Мы по-новому),

(32) Они в общем по-всякому.

К этой группе следует присовокупить некоторые наречные речения (для ясности они выделены жирным шрифтом), ср.

(33) Он, к сожалению, так себе,

(34) Родители как всегда <как обычно>, что им сделается,

(35) Она когда как <как когда >,

(36) Возможно, мой ум уже не такой острый, но физически я тиn-mon,

(37) Все окей, хороший тренировочный лагерь, мьл окей

(примеры (36) и (37) взяты из записей на интернет-форумах),

(38) Я сегодня что-то не очень.

С другой стороны, большое число наречий, обозначающих внутреннее состояние, в этих конструкциях не фигурирует совсем: трудно представить себе высказывания типа *Я грустно, *Я печально, *Я весело, *Я смешно, *Я неудобно, *Я стыдно и т.п. Иногда слова, которые, казалось бы, семантически очень близки, почти синонимичны, по отношению к сравниваемым конструкциям ведут себя по-разному: можно сказать и Мне плохо, и Я плохо, однако Мне дурно возможно, а *Я дурно - нет.

Для некоторых наречий наблюдается обратная картина: они фигурируют в конструкциях с номинативным подлежащим, но не встречаются с дательным субъектом, ср. приемлемые выражения типа (30-32) и неприемлемое

(39) *Мне по-разному <по-всякому, по-старому, окей ${ }^{4}>$.

Некоторые единицы, выступающие в рассматриваемой конструкции с номинативом, заслуживают особого внимания. Мы имеем в виду, в частности, наречие ничего и наречное речение так себе: в отличие от основного массива наречий, формирующих конструкцию, они могут характеризовать и сущности вне личной сферы говорящего, ср.

\footnotetext{
${ }^{4}$ Конструкция типа мне окей в современном разговорном языке допустима, но использует другое значение окей: нравится, не возражаю, не против. Заметим, что в этом значении окей абсолютно несовместима с номинативным подлежащим.
}

Славистика XXII/1 (2018) 
(40) Мама неважно

(мама входит в личную сферу собеседника и болеет или находится в плохой жизненной ситуации), но не

\section{(41) ?Компьютер неважно}

(такая фраза могла бы быть приемлемой разве что в случае, если речь идет о дорогом для говорящего компьютере, играющем важную роль в его жизни, и скорее всего говорящий этот компьютер персонифицировал бы).

Однако выражения типа

(42) Мама ничего <так себе> и

(43) Этот компьютер ничего <так себе >

оказываются равно допустимыми. Представляется, что в (42) и (43) мы имеем дело с разными лексическими значениями единиц ничего и так себе. В (42) идет речь о здоровье или о жизненной ситуации (обозначим эти наречия как ничего $o^{I}$ и так себе $\mathrm{e}^{l}$ ), а в (43) - о качестве предмета (обозначим соответствующие наречия как ничего 2 и так себе $)^{5}$. Добавим, что, строго говоря, эти наречия не привязаны к онтологическому классу подлежащего: в экстраординарных ситуациях ничего ${ }^{2}$ или так себе $e^{2}$ может относиться и к человеку, ср.

(44) Эта девушка ничего ${ }^{2}$, симпатичная,

а ничего или так себе $e^{l}$ к вещи, ср.

(45) Компьютер уже так себе ${ }^{1}$, клавиши разболтались, дисплей пошел трещинами, пора менять.

Разумеется, в словаре (и особенно в компьютерном словаре, рассчитанном на автоматическую обработку текстов) принадлежность наречия к данному классу должна специально отмечаться, например, посредством приписывания такому наречию особого синтаксического признака (как это делается, в частности, в лингвистическом процессоре ЭТАП-3; см. Apresjan et al. 2003; Iomdin et al. 2012).

\section{5. Не эллипсис ли?}

На первый взгляд может показаться, что рассматриваемые здесь конструкции допускают альтернативную синтаксическую трактовку - как результат глагольного эллипсиса:

(46а) Как Вася? > (46б) Как поживает Вася?,

(47а) Мама получше > (47б) Мама чувствует себя получше.

Это предположение представляется нам неверным.

Во-первых, речь здесь может идти не о конкретном элидированном глаголе, а о некотором конструкте достаточно размытой семантики. В качестве аналогии можно привести пару единиц совершенно другого лексического класса, которые различаются между собой уровнем имплицитности — это вопросительные единицы какой и что за. Последняя отличается от первой, в частности, тем, что апеллирует к некоторому скрытому факту действительности. Ср. вопрос

\footnotetext{
${ }^{5} \mathrm{~B}$ качестве курьеза заметим, что от так себе ${ }^{2}$ образуются сленговые прилагательные таксебешный и таксебеторный (компьютер таксебешный), которые у так себе $e^{l}$ начисто отсутствуют (*мама таксебеторная).
} 
(48) Какой у него номер телефона?,

предполагающий простой ответ типа 125-30-40, и вопрос

(49) Что у него за номер телефона?,

такого ответа решительно не допускающий (а предполагающий раскрытие имплицитной информации, скажем, принадлежности к определенному типу оператора, региону и т.д.)

Примерно так же различаются высказывания (47a) и (47б): высказывание Мама получше допускает естественное продолжение типа Она даже с соседкой помирилась, которое может выступать как объяснение ( $\approx$ раскрытие имплицитной информации), почему говорящий оценивает изменение ситуации с мамой к лучшему, в то время как высказывание

(50) Мама чувствует себя получше, даже с соседкой помирилась

представляется алогичным, даже загадочным.

Во-вторых, предположение об эллиптичности плохо совмещается с наличием у конструкции вариантов с реальной глагольной связкой (обычно в прошедшем времени), $c p$.

(51) Жанна вчера была получше, ходила гулять (НКРЯ).

В таком случае для эллипсиса глагола просто не остается места.

Таким образом, мы имеем дело с полноценной предикативной конструкцией, которая должна занять свое место в грамматике и словаре русского языка.

6. Что дальше?

В заключение стоит отметить, что по существу мы ввели в научный оборот новый класс конструкций микросинтаксиса. К нему, однако, тесно примыкают конструкции, которые требуют отдельного дополнительного исследования.

Это, во-первых, номинативные конструкции, в которых вместо наречий выступают предложные адвербиалы (ср. Я хорошо и

(52а) Я в полном порядке $<$ я в печали, Я в восторге $>-$ при невозможности

(52б) *Мне в полном порядке < *Мне в печали, *Мне в восторге>.

Во-вторых, это конструкции, в которых субъект выражается не именительным и не дательным падежом, а предложно-падежной формой типа $c X$-ом, как в

(53) Этот дикий человек опять заболел, опять с ним нехорошо (А. П. Чехов, Вишневый сад).

В-третьих, представляют интерес конструкции с предикативным наречием и номинативным подлежащим, представляющим собой свертку целой ситуации, как в выражениях типа

(54) Одна голова хорошо, а две лучше,

(55) Правда хорошо, а счастье лучше (А. Н. Островский),

(56) Паровоз - хорошо, / Пароход - хорошо, / Самолёт - ничего, / А олени лучше! (В. Бахнов, Я. Костюковский, Песенка оленевода), 
(57) И когда я вдруг узнала / мне стало очень грустно / конечно / что он только красный / что один ивет как-то нехорошо для флага. $($ Н. Н. Лосский и др. Транскрипт беседы Ивана Толстого с семьей Лосских // Передача «Мифы и репутации» на Радио Свобода 24.01.07, 2007).

Наконец, в-четвертых, заслуживают внимания микросинтаксические конструкции пространственной и временно́й локализации, в которых достаточно причудливо соотносятся именительный и дательный падежи субъекта.

Так, направительные конструкции типа $T \mathrm{bl} к y д а$ и Тебе куда, Я туда $<_{\boldsymbol{B}}$ Москву> и Мне туда <в Москву> равно допустимы, хотя и не синонимичны, в то время как конструкции чистой локализации или времени типа $T b l 2 d e, T b l$ откуда, Я (не вовремя) никакой вариативности не допускают: невозможно ни *Тебе где, ни Тебе откуда, ни *Мне (не) вовремя.

Все эти явления еще предстоит исследовать.

\section{Использованная литература}

Апресян, Юрий Д., Игорь М. Богуславский, Леонид Л. Иомдин, Владимир 3. Санников. Теоретические проблемы русского синтаксиса: Взаимодействие грамматики и словаря (отв. ред.) Ю. Д. Апресян. Москва: Языки славянских культур, 2010.

Добровольский, Дмитрий О. «Грамматика конструкций и фразеология». Вопросы языкознания 3, 2016: 7-21.

Иомдин, Леонид Л. «Хорошо меня там не было: синтаксис и семантика одного класса русских разговорных конструкций». [B:] Сб. статей “Grammaticalization and Lexicalization in the Slavic Languages”. По материалам Международного симпозиума «Грамматикализация и лексикализация в славянских языках», 11-14 ноября 2011 г. München-Berlin-Washington/ D.C.: Verlag Otto Sagner. Band 55, 2014, 423-436.

Иомдин, Леонид Л. «Конструкции микросинтаксиса, образованные русской лексемой раз». Slavia, časopis pro slovanskou filologii 84/3, 2015: 291-306.

Иомдин, Леонид Л. «Между синтаксической фраземой и синтаксической конструкцией. Нетривиальные случаи микросинтаксической неоднозначности». Slavia, časopis pro slovanskou filologii 86/2-3, 2017, 230-243.

Летучий, Александр В. «Синтаксические свойства сентенциальных актантов при предикативах». Rhema/Рема. Вестник МГГУ им. М.А.Шолохова. Сер. Филологические науки 1 , 2014, 62-84.

Рахилина, Екатерина В. Лингвистика конструкций. Москва: Издательский центр «Азбуковник», 2010.

Циммерлинг, Антон В. «Именные предикативы и дативные предложения в европейских языках». [В:] Компьютерная лингвистика и интеллектуальные технологии. Вып. 9 (16). Материалы международной конференции «Диалог 2010». Москва, 2010, 549 -558.

Циммерлинг, Антон В. «Неканонические подлежащие в русском языке». [В:] М. Воейкова (отв. ред.) От формы к значению, от значения к форме. Сб. статей в честь 80-летия А. В. Бондарко. Москва: Языки славянских культур, 2012, 568-590.

Циммерлинг, Антон В. «Русские предикативы в зеркале эксперимента и корпусной грамматики». [B:] Компьютерная лингвистика и интеллектуальные технологии. По материалам ежегодной международной конференции «Диалог» 16, т. 2. Москва, 2017, 466-482.

Apresjan, Juri, Igor Boguslavsky, Leonid Iomdin, Andrei Lazursky, Vladimir Sannikov, Victor Sizov, Leonid Tsinman. "ETAP-3 Linguistic Processor: a Full-Fledged NLP Implementation of the MTT”. [In:] First International Conference on Meaning-Text Theory (MTT'2003). Paris: École Normale Supérieure, 2003, 279-288.

Iomdin, Leonid, Vadim Petrochenkov, Victor Sizov, Leonid Tsinman. "ETAP parser: state of the art". [In:] Computational Linguistics and Intellectual Technologies. International Conference 
(Dialog'2012). Moscow: RGGU Publishers 11(18), 2012, 830-843.

Say, Sergey. "On the nature of dative arguments in Russian constructions with "predicatives". [In:] Irina Kor Chahine (ed.) Current studies in Slavic linguistics. Amsterdam, Philadelphia: John Benjamins, 2013, 225-246. [Studies in Language Companion Series 146].

\title{
Леонид Иомдин
}

\section{О ПОЈЕДИНИМ РАЗГОВОРНИМ КОНСТРУКЦИЈАМА СА ПРЕДИКАТИВНИМ ПРИЛОЗИМА У РУСКОМ ЈЕЗИКУ}

\author{
Резиме
}

У раду се истражује релативно нови тип руских разговорних конструкција са прилогом у функцији предиката и субјектом у номинативу, попут: $T$ bы как? - Я хорошо <отлично, пло$x o$, неважно $>$. Такве конструкције се разматрају у поређењу са безличним конструкцијама са адвербијалним предикатом и субјектом у дативу, које су већ добро проучене у руском језику, попут: Мне хорошо <отлично, плохо, весело, грустно>, као и низом других сличних конструкција.

Показано је да разматрани тип конструкција поседује низ специфичних синтаксичких и семантичких карактеристика. У прве, конкретно, спада чињеница да је субјекат стања у номинативу, што није типично за руске конструкције са неконгруентним предикатом који описује стање субјекта. Према мишљењу аутора, такве појаве у језику треба разматрати као микросинтаксичке.

Међу семантичким показатељима издваја се то да таква конструкција реферише о личној говорниковој сфери, као и чинилац одређеног трајања ситуације чији је учесник субјекат реченице. Такви показатељи нису типични за конструкције са субјектом у дативу, које не реферишу о личној говорниковој сфери и могу указивати на моменталне ситуације.

Детаљно се истражује лексички састав прилога и прилошких израза који се могу јављати у таквим конструкцијама. Истиче се да су у основи те лексичке групе прилози позитивне и негативне оцене (хорошо, чудесно, плохо, отвратительно итд.), као и поредбени прилози (по-разному, по-старому и сл.). Испоставља се да се прилози који се јављају у овом типу конструкција суштински укрштају са оним који су заступљени у конструкцијама са дативом субјекта, али већи број прилога припада само једном од тих типова. На пример, прилози поразному и по-старому могу се јавити само у конструкцијама са номинативом субјекта, а весело и стылдно - само у конструкцијама са дативом.

На крају се наводе примери конструкција које су семантички и синтаксички блиске оним које чине предмет истраживања. То су: (1) конструкције са адвербијалним предикатом, попут $Я$ в печали, (2) конструкције у којима се субјекат не јавља у облику номинатива или датива, већ је заступљен предложно-падешком конструкцијом, попут $C$ ним нехорошо, (3) конструкције у којима субјекат у номинативу језгровито дочарава целу ситуацију (Одна голова хорошо, а две лучше) и (4) конструкције локативне и темпоралне оријентације, у којима се на занимљив начин смењују субјекат у номинативу и дативу (mы куда и тебе куда, али само ты где, я не вовремя уз забрану на *тебе где и *мне не вовремя). Аутор намерава да посвети истраживању таквих конструкција посебан рад.

Кључне речи: руски језик, микросинтакса, предикативне конструкције, предикативни прилози, номинатив субјекта, датив субјекта. 